\title{
INVESTIGATING THE THERMAL AND STRUCTURAL RESPONSES IN HARD-FACING APPLICATION WITH THE GTAW PROCESS
}

\author{
Atilla Savaş \\ Piri Reis University, Tuzla/Istanbul, Turkey \\ e-mail: asavas@pirireis.edu.tr
}

The gas tungsten arc welding (GTAW) process is an excellent way of performing quality hard-facing applications. The residual stresses and distortions are encountered in hard-facing. There are several methods to decrease residual stresses. Changing the welding pattern, changing thickness and preheating can be mentioned for this purpose. In this work, the influence of the welding pattern, plate thickness and preheating was investigated. The temperature distribution with the same welding conditions was used for validation of the numerical model. The total deformation in a $2 \mathrm{~mm}$ plate was 15 times higher than in a $6 \mathrm{~mm}$ plate with the same welding conditions.

Keywords: hard-facing, moving heat source, two-way coupling, gas tungsten arc welding (GTAW), FEM

\section{Introduction}

Residual stresses and distortions are very important in plates subjected to hard-facing. Permanent deformations and residual stresses can influence the service life of manufactured parts. There are some modeling efforts calculating the residual stresses and deformations in welded parts and parts subjected to hard-facing. A thermal elastic-plastic finite element method based on ABAQUS code was developed to estimate inherent deformations for different small-scale welding joints by Deng et al. (2007). The total strain was computed as elastic strain plus plastic strain and thermal strain. Chen et al. (2014) used temperature-dependent material properties of St37 in their work. The temperature distributions parallel to the weld centerline were used for validation purposes. The same experimental results were used in this work to validate the temperature distribution in the hard-facing process. Thermomechanical analyses for different welding processes such as gas tungsten arc welding (GTAW), gas metal arc welding (GMAW) and shielded metal arc welding (SMAW) were investigated by Arora et al. (2019). The effect of the welding sequence on the temperature distribution and angular distortions was also studied. Double ellipsoidal and single ellipsoidal heat generation were compared. Varma Prasad et al. (2016) investigated the GTAW of a pipe. Double ellipsoidal moving heat source model was utilized and residual stresses and deformations were calculated at different positions on the pipe. The effects of the welding current and pipe thickness on the residual stress and temperature distribution at different locations were analyzed.

Goldak et al. (1984) were the first scientists to utilize the double ellipsoidal moving heat source in welding simulation. Beforehand, the Gaussian moving heat source was popular. They compared two models and found that the double ellipsoidal moving heat source model was more useful in predicting the temperature history. Gery et al. (2005) used the double ellipsoidal heat source model to simulate butt welding. They predicted the fusion zone and heat affected zone sizes very well. Submerged arc welding (SAW) was investigated by Nezamdost et al. (2016). 
They utilized modified Goldak heat source models. They calculated both 2D axisymmetric and 3D models. The results were very close to each other. Their predictions were in good agreement with the experiments. Elastic strain, plastic strain and thermal strain were taken into account. Thermo-mechanical analysis of $6 \mathrm{~mm}$ thick multi-pass welding was carried out by Zubairuddin et al. (2017). They declared that preheating of the plates could decrease deformations. The predicted results were validated with experimental measurements. Attarha and Sattari-Far (2011) studied 3D finite element simulation of GTAW for three joints (two similar and one dissimilar) comprised of AISI type 304 stainless steel and St37 carbon steel thin plates. They were only interested in temperature history; residual stresses were not calculated. A thermo-elastoplastic FE analysis, considering material and geometrical non-linearity, was utilized to simulate temperature, residual stresses, and distortion by Venkatkumar et al. (2018). Material and geometric nonlinearity were taken into account. Maximum distortion was not greater than $25-30 \%$ of a millimeter. They utilized the double ellipsoidal heat source and the combined heat transfer coefficient for convection and radiation. The influence of moving heat source parameters on the temperature and residual stress distribution for a GTAW circumferential butt joint of AISI 304 stainless steel was investigated by Ravisankar et al. (2014). They chose to use the Goldak double ellipsoidal heat source model. In calculating the residual stresses, they took into account the elastic strain, plastic strain, thermo-metallurgical strain and strain due to phase transformation. A new heat source model based on elliptic paraboloid geometry to predict the welding heat input was proposed by García-García et al. (2016). The mathematical model of the GTAW process thermal field was solved numerically employing FVM, and its results were compared against the thermal history measured experimentally. A non-linear transient thermal analysis was performed to obtain the temperature history generated during the laser beam welding (LBW) process by Chandelkar and Pradhan (2020). Numerical calculations were conducted through ANSYS APDL of laser welding for various laser powers.

Moselli et al. (2013) analyzed a mild steel substrate covered with Stellite 6 using GTAW hard-facing application. They concluded that GTAW produced a hard coating with deposition of Stellite 6 in a powder form directly into the weld puddle. Thick and thin plates of steel were examined by Lazić et al. (2015). They wanted to predict distortions occurring in hard-facing applications. Zhao et al. (2018) studied one cobalt-based and three iron-based hard-facing alloys undergoing bending loading. The residual elastic strain was measured. Plasma jet hard-facing modeling was performed by Zamorskiy (2016). He utilized ANSYS and simulated both parts of the welding process, the arc and the weld pool. Lazić et al. (2016) investigated residual stresses in thin and thick plates. They measured values of the residual stresses for hard-facing of thick plates; they were higher than the values for thin plates. Wu et al. (2000) simulated residual stresses in hard-faced structural steel. They calculated that the residual stresses in the hard-faced part were dependent on several factors, i.e. the heat-transfer coefficient, the thermal expansions coefficient, thickness of the substrate and preheating temperature. The review of hard-facing applications was performed by Ramesh (2010). He analyzed substrates, welding methods and consumables. He concluded that hard-facing could be done on any steel material using a wide variety of welding processes. Laser gas-assisted nitriding of steel was considered and the residual stress developed after the nitriding process was examined numerically as well as experimentally by Yilbas et al. (2010). Yang et al. (2004) calculated temperature and residual stress distribution of hardfaced specimens. The results were in accordance with the experimental data.

Zargar et al. (2016) involved in how the welding sequence influenced residual stresses and deformations. There is a lack of research work studying the effects of welding patterns during hard-facing. In this work, a low carbon steel hard-facing process is investigated to minimize the residual stresses and deformations. The present work does not consider the filler material, only melting of the base metal is taken into account. The effect of the welding sequence, preheating temperature and plate thickness is analyzed. 
The material properties of St37 steel were taken as temperature-dependent. The plastic part of the true stress-true strain diagram was applied with respect to the bi-linear isotropic hardening model. The novelty in this work is that the temperature and displacement coupling is bi-directional. In this way, the solutions will be more likely to represent the actual situation. In the residual stress calculations, elastic strain, plastic strain and thermal strain are taken into account. The hard-facing pattern is altered, and thickness and the initial temperature of the substrate are changed to analyze their influence on deformations and residual stresses.

\section{Welding simulation}

The thermal part of the welding simulation includes conduction, convection and radiation. The structural part of the model takes into account the elastic, plastic and thermal strain. The temperature-dependent thermophysical properties of St37, i.e. the conduction coefficient, the specific heat and density have been taken from the work of Chen et al. (2014). The temperature-dependent thermomechanical properties of St37, i.e. the modulus of elasticity, the Poisson ratio and the coefficient of thermal expansion were also taken from the same reference (Table 1). The chemical composition of St37 is tabulated in Table 2 (Anon n.d.). The moving heat source model was chosen as a double ellipsoidal heat source. The parameters of this model are selected values as in the work by Chen et al. (2014) and given in Table 3. The model of the moving heat source can be seen in Fig. 1 (Xavier et al., 2015). The thermal part and the structural part are mutually coupled, i.e. the temperature gradient causes strains to form and, on the other hand, the deformation that takes place in the melting zone and the HAZ causes temperature changes.

Table 1. Thermo-physical and thermo-mechanical properties of St37

\begin{tabular}{|c|c|c|c|c|c|c|}
\hline $\begin{array}{c}\text { Tempe- } \\
\text { rature } \\
{\left[{ }^{\circ} \mathrm{C}\right]}\end{array}$ & $\begin{array}{c}\text { Density } \\
{\left[\mathrm{kg} / \mathrm{m}^{3}\right]}\end{array}$ & $\begin{array}{c}\text { Specific } \\
\text { heat } \\
{\left[\mathrm{J} /\left(\mathrm{kg}^{\circ} \mathrm{C}\right)\right]}\end{array}$ & $\begin{array}{c}\text { Conduct- } \\
\text { ivity } \\
{\left[\mathrm{W} /\left(\mathrm{m}^{\circ} \mathrm{C}\right)\right]}\end{array}$ & $\begin{array}{c}\text { Young's } \\
\text { modulus } \\
{\left[10^{9} \mathrm{~Pa}\right]}\end{array}$ & $\begin{array}{c}\text { Poisson's } \\
\text { ratio }\end{array}$ & $\begin{array}{c}\text { Thermal } \\
\text { expansion } \\
\text { coeff. } \\
{\left[10^{-7} /{ }^{\circ} \mathrm{C}\right]}\end{array}$ \\
\hline \hline 0 & 7900 & 444 & 45.9 & 205 & 0.33 & 120 \\
\hline 100 & 7880 & 472 & 44.8 & 202.5 & 0.34 & 122 \\
\hline 200 & 7830 & 503 & 43.4 & 200 & 0.35 & 124 \\
\hline 300 & 7790 & 537 & 41.4 & 187.5 & 0.36 & 126 \\
\hline 400 & 7750 & 579 & 38.9 & 175 & 0.37 & 128 \\
\hline 600 & 7660 & 692 & 33.6 & 148 & 0.39 & 132 \\
\hline 800 & 7560 & 837 & 28.7 & 100 & 0.41 & 136 \\
\hline 1200 & 7370 & 860 & 28.6 & 17.5 & 0.45 & 144 \\
\hline 1300 & 7320 & 863 & 29.5 & 15 & 0.46 & 146 \\
\hline 1500 & 7320 & - & - & 10 & 0.48 & 150 \\
\hline
\end{tabular}

Table 2. Chemical composition of St37

\begin{tabular}{|c|c|c|c|c|c|c|}
\hline $\begin{array}{c}\text { Steel } \\
\text { grade }\end{array}$ & $\begin{array}{c}\text { Carbon } \\
\max [\%]\end{array}$ & $\begin{array}{c}\text { Silicon } \\
{[\%]}\end{array}$ & $\begin{array}{c}\text { Manganese } \\
{[\%]}\end{array}$ & $\begin{array}{c}\text { Phosphorus } \\
\max [\%]\end{array}$ & $\begin{array}{c}\text { Sulfur } \\
\max [\%]\end{array}$ & $\begin{array}{c}\text { Nitrogen } \\
\max [\%]\end{array}$ \\
\hline \hline ST37 & 0.20 & $0.15-0.35$ & $0.35-0.75$ & 0.050 & 0.050 & 0.011 \\
\hline
\end{tabular}


Table 3. The Goldak double ellipsoidal parameters for welding simulation

\begin{tabular}{|l|c|}
\hline$a$ - parameter in $x$-direction & $5 \mathrm{~mm}$ \\
\hline$b_{f}$ - parameter in $y$-direction, front & $5 \mathrm{~mm}$ \\
\hline$b_{r}$ - parameter in $y$-direction, rear & $15 \mathrm{~mm}$ \\
\hline$c$ - parameter in $z$-direction & $5 \mathrm{~mm}$ \\
\hline$f_{f}$ - front fraction & 0.5 \\
\hline$f_{r}$ - rear fraction & 1.5 \\
\hline Welding speed & $8.33 \mathrm{~mm} / \mathrm{s}$ \\
\hline$U$ - welding voltage & $27 \mathrm{~V}$ \\
\hline$I-$ welding current & $125 \mathrm{~A}$ \\
\hline$\eta-$ welding efficiency & 0.9 \\
\hline$Q-$ heat input, $Q=\eta I U$ & $3037.5 \mathrm{~W}$ \\
\hline
\end{tabular}

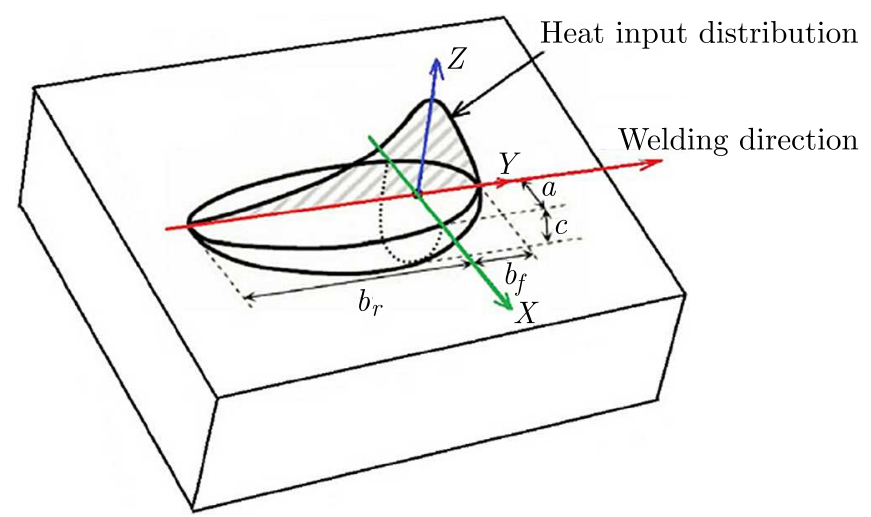

Fig. 1. Schematic model for the double ellipsoidal heat source

\section{Numerical model}

The hard-facing patterns are shown in Figs. 2a and 2b. The fixed supports are depicted in Fig. 2c. In order to decrease distortions and residual stresses, one can use several methods. Eight different models, four for the $2 \mathrm{~mm}$ thick plates and four for the $6 \mathrm{~mm}$ thick plates are analyzed. The influence of plate thickness, preheating temperature $\left(300^{\circ} \mathrm{C}\right)$ and the welding pattern was investigated by analyzing the FEM solutions. The utilized welding conditions were $27 \mathrm{~V}, 125 \mathrm{~A}$, and $8.33 \mathrm{~mm} / \mathrm{s}$. In Figs. 2a and 2b, one can also see the mesh constructed for the ANSYS FEM model. There are two paths for which the distortions and residual stresses are given. These paths are shown in Fig. 3. The most important part of the model is the heat supplied by the moving heat source. The two parts of the Goldak double ellipsoidal moving heat source model are given in the following equations

$$
\begin{aligned}
& q_{f}(x, y, z)=\frac{6 \sqrt{3} f_{f} Q}{a b_{f} c \pi \sqrt{\pi}} \exp \left(-\frac{3 x^{2}}{a^{2}}-\frac{3 y^{2}}{b_{f}^{2}}-\frac{3 z^{2}}{c^{2}}\right) \\
& q_{r}(x, y, z)=\frac{6 \sqrt{3} f_{r} Q}{a b_{r} c \pi \sqrt{\pi}} \exp \left(-\frac{3 x^{2}}{a^{2}}-\frac{3 y^{2}}{b_{r}^{2}}-\frac{3 z^{2}}{c^{2}}\right)
\end{aligned}
$$

Here $q_{f}$ is the forward part and $q_{r}$ is the rear part of the heat source. The convective heat transfer coefficient and the radiation emissivity are assumed to be temperature-dependent and are given in Eq. (3.2) (García-García et al., 2018). The ambient temperature is assumed to be $20^{\circ} \mathrm{C}$. The outer corners of the panels are selected as fixed supports by ANSYS (Fig. 2c). The ANSYS transient structural module is used, and the thermal analysis is performed according to the APDL code. The temperature-dependent material properties are also given as the APDL code. 
(a)

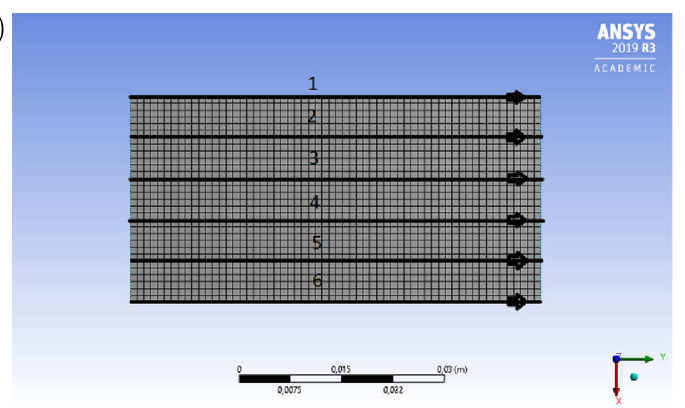

(b)



(c)



Fig. 2. (a) Straight welding pattern and mesh. (b) Cross welding pattern and mesh. (c) Position of fixed supports

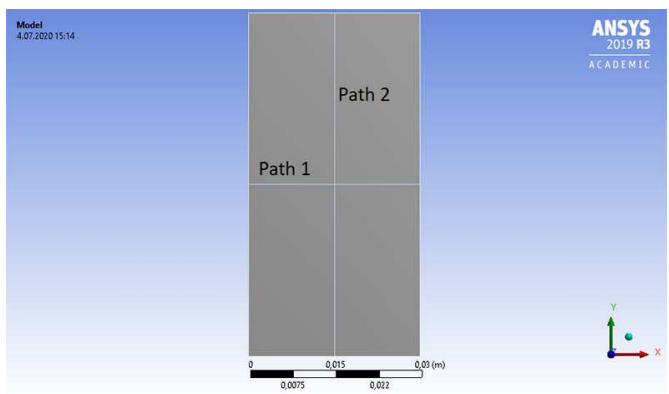

Fig. 3. Path definitions

The element type is SOLID 226, and the elements are hexahedra geometrically. Mesh sizes for the $2 \mathrm{~mm}$ and $6 \mathrm{~mm}$ thick plates are $1 \mathrm{~mm} \times 1 \mathrm{~mm} \times 1 \mathrm{~mm}$ and $1 \mathrm{~mm} \times 1 \mathrm{~mm} \times 3 \mathrm{~mm}$, respectively. There are 3600 elements and 20525 nodes in the problem domain. The Preconditioned Conjugate Gradient (PCG) iterative equation solver is utilized to solve nonlinear transient problems. Large deformations are considered

$$
h= \begin{cases}0.0668 T & \text { for } \quad 0^{\circ} \mathrm{C}<T<500^{\circ} \mathrm{C} \\ 0.231 T-82.1 & \text { for } T>500^{\circ} \mathrm{C}\end{cases}
$$

The governing equations for the thermal and mechanical parts are given below.

The three-dimensional non-linear heat transfer equation can be written as

$$
\rho C \frac{\partial T}{\partial t}(x, y, z, t)=-\nabla \cdot(-k \nabla T)+Q(x, y, z, t)
$$

Here, $\rho$ stands for density and has a unit of $\mathrm{kg} / \mathrm{m}^{3}, C$ is the heat capacity and its unit is $\mathrm{W} / \mathrm{m}^{\circ} \mathrm{C}$. $\nabla$ is the spatial gradient operator. $k$ is the thermal conductivity coefficient and has a unit of $\mathrm{W} / \mathrm{m}^{\circ} \mathrm{C} . x, y, z$ are cartesian coordinate axes and $t$ is time. $Q$ stands for the heat input and is measured in watts. 
The plastic deformation is associated with the following von Mises criterion

$$
\sigma_{e}=\sqrt{\frac{1}{2}\left[\left(\sigma_{1}-\sigma_{2}\right)^{2}+\left(\sigma_{2}-\sigma_{3}\right)^{2}+\left(\sigma_{3}-\sigma_{1}\right)^{2}\right]}
$$

Here, $\sigma_{e}$ is the equivalent stress and $\sigma_{1}, \sigma_{2}, \sigma_{3}$ are the principal stresses.

The total strain can be given by the following equation

$$
\varepsilon_{\text {total }}=\varepsilon_{\text {elastic }}+\varepsilon_{\text {plastic }}+\varepsilon_{\text {thermal }}
$$

The stress and displacement fields can be computed by the following equation combining the equilibrium and constitutive equations

$$
\mathbf{K}_{1} \mathbf{U}-\mathbf{K}_{2} \mathbf{T}=\mathbf{R}
$$

where $\mathbf{K}_{1}$ and $\mathbf{K}_{2}$ are the stiffness matrices, $\mathbf{U}$ is the displacement vector, $\mathbf{T}$ is the temperature field and $\mathbf{R}$ is the temperature loads of each node.

The strain hardening effect can be depicted in Fig. 4. Here, $E$ stands for Young's modulus and $E_{t}$ stands for the tangent modulus. This behavior is called bi-linear isotropic hardening and simplifies the numerical solution.

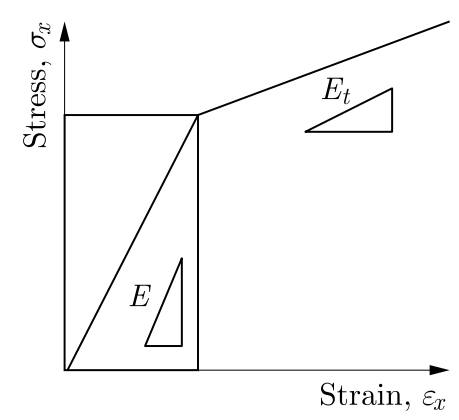

Fig. 4. The plot of the strain hardening effect

\section{Validation}

To verify the finite element model, two groups of plates are modeled and simulated in ANSYS. The dimensions of the plate are $300 \mathrm{~mm} \times 150 \mathrm{~mm} \times 4 \mathrm{~mm}$ and $300 \mathrm{~mm} \times 150 \mathrm{~mm} \times 6 \mathrm{~mm}$, which are identical to experiment number 1 from the work of Chen et al. (2014). The temperature distribution comparisons are given in Figs. 5a and 5b. The agreement between the experiment and the model, especially at higher temperatures, can be followed by the given figures. Validation of the structural part has also been performed according to the same experiment. The maximum deformation in the butt-welded plate was $4.5 \mathrm{~mm}$ in the experiment, whereas it was $3.5 \mathrm{~mm}$ in the $4 \mathrm{~mm}$ plate model. This makes an error of $22 \%$. The longitudinal stress along the weld centerline is $328 \mathrm{MPa}$ according to the same experiment. The present model predicts the longitudinal stress as $312 \mathrm{MPa}$. The error percentage is 4.8 .

\section{Results and discussion}

The mesh independence analysis was performed according to total deformations. The simulation was run for the $2 \mathrm{~mm}$ thick plate, the initial temperature was $20^{\circ} \mathrm{C}$, and the welding pattern was straight (Fig. 2a). In Fig. 6, one can see that approximately 20000 nodes can be sufficient to do a mesh-independent solution for this problem domain. 

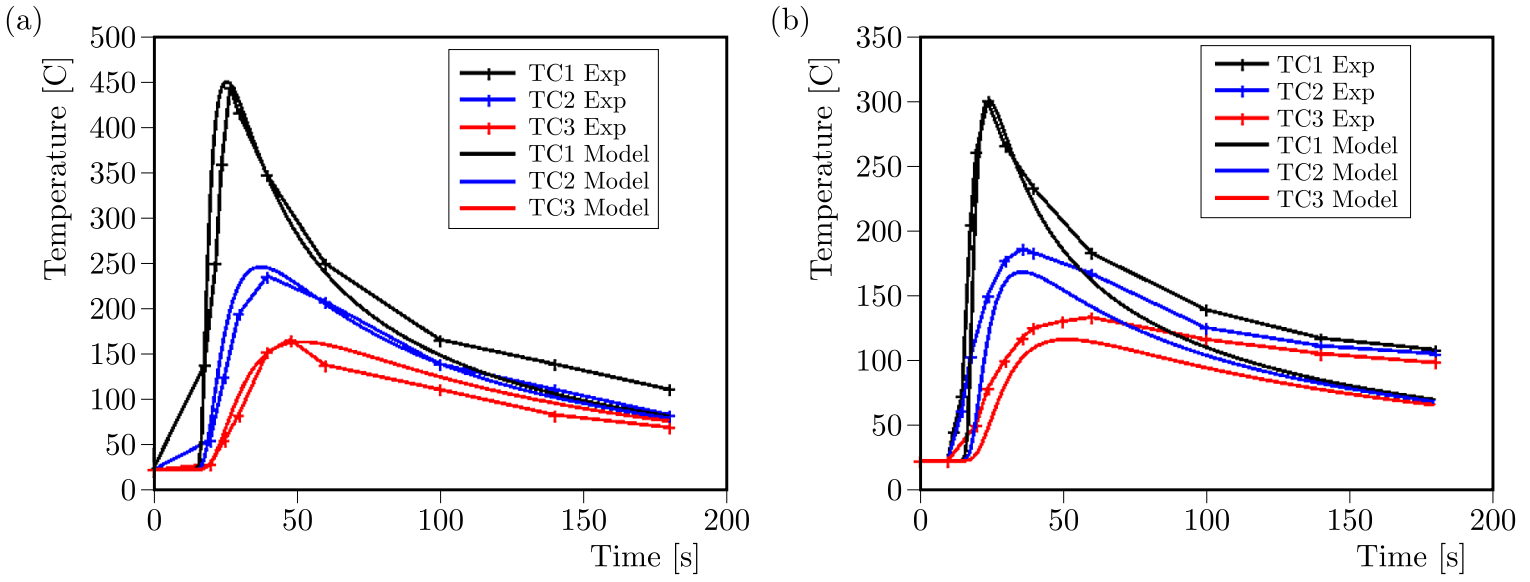

Fig. 5. Plate temperature comparison: (a) $4 \mathrm{~mm}$, (b) $6 \mathrm{~mm}$

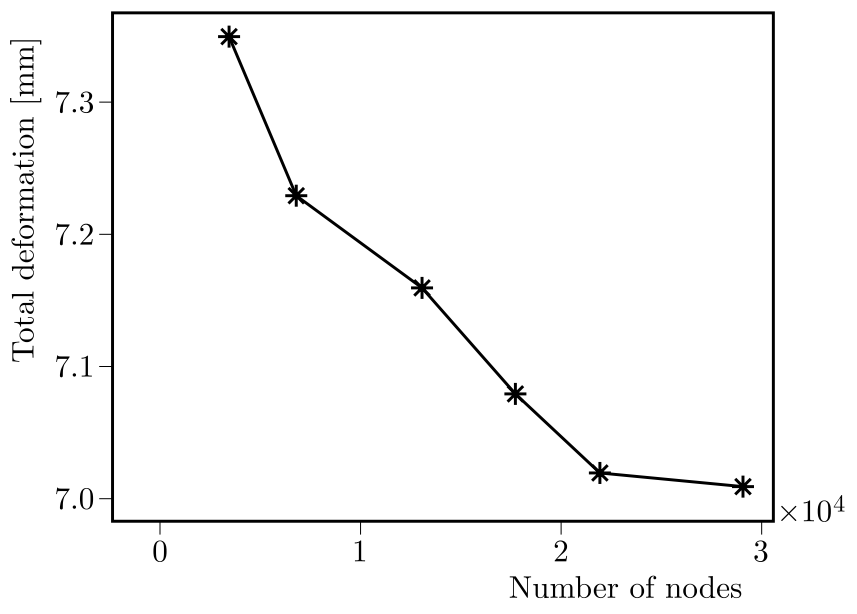

Fig. 6. Mesh independence analysis

After the validation has been performed, the same double ellipsoidal heat source parameters were utilized for two plates with different thicknesses. Hard-facing was applied to $30 \mathrm{~mm} \times 60 \mathrm{~mm} \times 2 \mathrm{~mm}$ (model 1) and $30 \mathrm{~mm} \times 60 \mathrm{~mm} \times 6 \mathrm{~mm}$ (model 2). In model 1, a $2 \mathrm{~mm}$ thick plate was modeled, and the temperature results for the time at 60 seconds (which coincides with the end of the hard-facing application) and for $41 \mathrm{~s}$ are given in Figs. $7 \mathrm{a}$ and $7 \mathrm{~b} .41$ seconds correspond to the fifth pass welding (see Fig. 2a). $Q$ value in equations (3.1) is selected as $1500 \mathrm{~W}$, which can be decomposed into: $15 \mathrm{~V} \times 111 \mathrm{~A} \times 0.9$ (efficiency of welding process). Welding speed is taken as $6 \mathrm{~mm} / \mathrm{s}$, therefore a 6 pass welding along the $y$ axis (Fig. 2a) corresponds to $60 \mathrm{~s}$. In Figs. $8 \mathrm{a}$ and $8 \mathrm{~b}$, one can see again the temperature distribution at $60 \mathrm{~s}$ and $41 \mathrm{~s}$, respectively, for model 2. The welding pattern here is not straight but a cross pattern which can be seen in Fig. 2b. It is observed that with the same welding conditions, the maximum temperature attained in the process is decreased in the thick plate. When the aforementioned four figures are analyzed, one can see that the heat input is high enough to realize the melting of St37 plates.

In Fig. 9, the longitudinal (in $y$-direction) residual stresses are analyzed along path 2 (see Fig. 3). Straight and cross patterns, $20^{\circ} \mathrm{C}$ and $300^{\circ} \mathrm{C}$ initial temperature conditions are the important parameters for this analysis. In both $2 \mathrm{~mm}$ and $6 \mathrm{~mm}$ plates, when the initial condition is $20^{\circ} \mathrm{C}$ and the pattern is straight, a higher tensile residual stress is generally observed than for the other conditions. This can be explained by the softening effect of the preheating. In the 
(a)

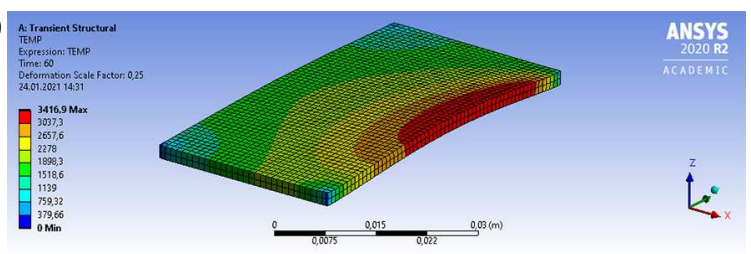

(b)

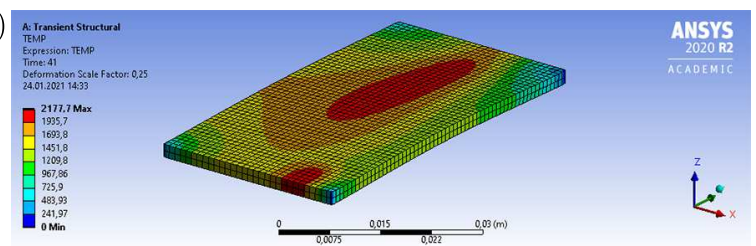

Fig. 7. Model 1 - temperature distribution at: (a) $60 \mathrm{~s}$, (b) $41 \mathrm{~s}$

(a)

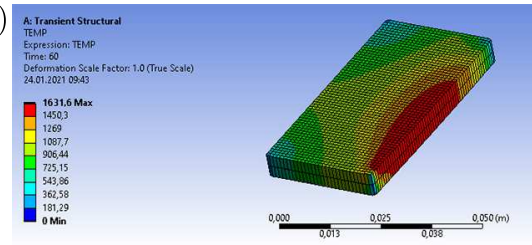

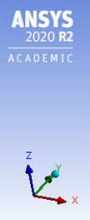

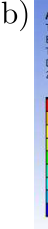



Fig. 8. Model 2 - temperature distribution at: (a) $60 \mathrm{~s}$, (b) $41 \mathrm{~s}$



Fig. 9. Longitudinal stress distribution along path $2,20^{\circ} \mathrm{C}$ vs. $300^{\circ} \mathrm{C}$ and straight vs. cross pattern (models 1 and 2)

$6 \mathrm{~mm}$ plate cross pattern, the residual stress values are compressive, and this pattern should be chosen to be on the safe side. The cross patterns produce higher stresses in the first half of path 2 in the $2 \mathrm{~mm}$ plate than the straight pattern. This is because of different cooling times of the two patterns.

The transverse residual stresses (in $x$-direction) along path 2 are shown in Fig. 10. The same conditions are valid in this figure too. The straight pattern, $20^{\circ} \mathrm{C}$ and $300^{\circ} \mathrm{C}$ initial temperatures in $2 \mathrm{~mm}$ plate gives higher stresses in the second half of the path than in the first half. In the first half of the pattern, it is vice versa. This can be explained again by different cooling times of the two patterns.

The total deformations along path 1 in $2 \mathrm{~mm}$ and $6 \mathrm{~mm}$ plates are given in Fig. 11. The straight pattern without preheating in the $2 \mathrm{~mm}$ plate gives the highest deformation. The deformations in the $6 \mathrm{~mm}$ plate cannot be distinguished from each other. The lowest deformation in the $2 \mathrm{~mm}$ plate was achieved in the straight pattern and with a $300^{\circ} \mathrm{C}$ preheating. The deformation in the $2 \mathrm{~mm}$ plate was approximately 15 times higher than in the $6 \mathrm{~mm}$ plate. 




Fig. 10. Transverse stress distribution along path $2,20^{\circ} \mathrm{C}$ vs. $300^{\circ} \mathrm{C}$ and straight vs. cross pattern (models 1 and 2)

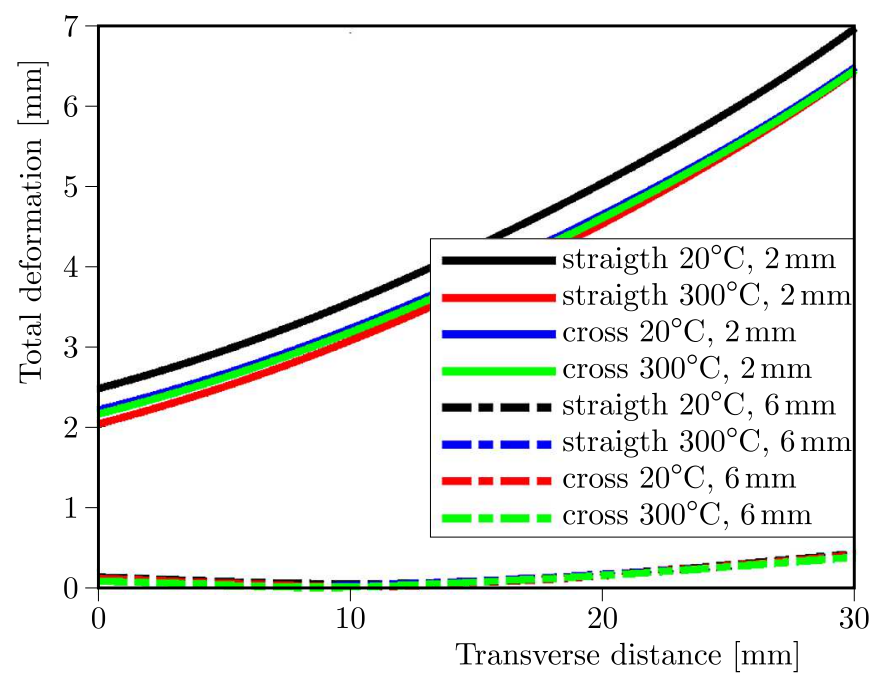

Fig. 11. Total deformations along path $1,20^{\circ} \mathrm{C}$ vs. $300^{\circ} \mathrm{C}$ and straight vs. cross pattern (models 1 and 2 )

\section{Conclusions}

- The experimental and model temperatures shown in the validation section coincide.

- In both $2 \mathrm{~mm}$ and $6 \mathrm{~mm}$ plates, when the initial condition is $20^{\circ} \mathrm{C}$ and the pattern is straight, a higher longitudinal tensile residual stress is generally observed than for the cross pattern and a $300^{\circ} \mathrm{C}$ preheating.

- The deformation in the $2 \mathrm{~mm}$ plate is approximately 15 times higher than in the $6 \mathrm{~mm}$ plate.

- In the $2 \mathrm{~mm}$ thick plate, the lowest deformation is observed in the straight pattern and with a $300^{\circ} \mathrm{C}$ preheating.

\section{References}

1. Anon. n.d. "ST37-2 Angle Steel - Low Carbon Steel For General Uses". Retrieved January 12, 2021 (https://www.steel-sections.com/steelsections/st37-2-angle-steel.html) 
2. Arora H., Singh R., Singh Brar G., 2019, Prediction of temperature distribution and displacement of carbon steel plates by FEM, Materials Today: Proceedings, 18, 3380-3386

3. Attarha M.J., Sattari-Far I. 2011, Study on welding temperature distribution in thin welded plates through experimental measurements and finite element simulation, Journal of Materials Processing Technology, 211, 4, 688-694

4. Chandelkar V., Pradhan S.K., 2020, Numerical simulation of temperature distribution and experimentation in laser beam welding of SS317L alloy, Materials Today: Proceedings, 27, 4

5. Chen B.Q., Hashemzadeh M., Soares C.G., 2014, Numerical and experimental studies on temperature and distortion patterns in butt-welded plates, International Journal of Advanced Manufacturing Technology, 72, 5-8, 1121-1131

6. Deng D., Murakawa H., Liang W., 2007, Numerical simulation of welding distortion in large structures, Computer Methods in Applied Mechanics and Engineering, 196, 45-48, 4613-4627

7. García-García V., Camacho-Arriaga J.C., Reyes-Calderón F., Castañeda-Morales C.E., 2018, Fluid structure interaction modeling of expansion-contraction deformation during welding in a spacer-band-blade assembly of a HP steam turbine diaphragm, Journal of Manufacturing Processes, 33, 203-218

8. García-García V., Camacho-Arriaga J.C., Reyes-Calderón F. 2016, A simplified elliptic paraboloid heat source model for autogenous GTAW process, International Journal of Heat and Mass Transfer, 100, 536-549

9. Gery D., Long H., Maropoulos P., 2005, Effects of welding speed, energy input and heat source distribution on temperature variations in butt joint welding, Journal of Materials Processing Technology, 167, 2-3, 393-401

10. Goldak J., Chakravarti A., Bibby M., 1984, A new finite element model for welding heat sources, Metallurgical Transactions B, 15, 299-305

11. Lazić V., Arsić D., Nikolić R., Aleksandrović S., Djordjević M., Hadzima B., Bujnak J., 2015, Experimental determination of deformations of the hard faced samples made of steel for operating at elevated temperatures, Procedia Engineering, 111, 495-501

12. Lazić V., Arsić D., Nikolić R.R., Hadzima B., 2016, Experimental determination of residual stresses in the hard-faced layers after hard-facing and tempering of hot work steels, Procedia Engineering, 153, 392-399

13. Moselli P.C., Falcão de Oliveira M., Moreno J.R.S., 2013, Wear resistance in hard-facing applied in substrate SAE 1020 using welding process gas tungsten arc welding (GTAW) alloy stellite 6 in powder form, Scientific Research and Essays, 8, 36, 1730-1740

14. Nezamdost M.R., Nekoui Esfahani M.R., Hashemi D.H., Mirbozorgi S.A., 2016, Investigation of temperature and residual stresses field of submerged arc welding by finite element method and experiments, International Journal of Advanced Manufacturing Technology, 87, 1-4. 615-624

15. RAMEsh A., 2010, A review paper on hard-facing processes and materials, International Journal of Engineering Science and Technology, 2, 11, 6507-6510

16. Ravisankar A., Kumar Velaga S., Rajput G., Venugopal S., 2014, Influence of welding speed and power on residual stress during gas tungsten arc welding (GTAW) of thin sections with constant heat input: a study using numerical simulation and experimental validation, Journal of Manufacturing Processes, 16, 2, 200-211

17. Varma Prasad V.M., Joy Varghese V.M., Suresh M.R., Siva Kumar D., 2016, 3D simulation of residual stress developed during TIG welding of stainless steel pipes, Procedia Technology, 24, 364-371

18. Venkatkumar D., Ravindran D., Selvakumar G., 2018, Finite element analysis of heat input effect on temperature, residual stresses, and distortion in butt welded plates, Materials Today: Proceedings, 5, 8328-8337 
19. Wu A.P., Ren J.L., Peng Z.S., Murakawa H., Ueda Y., 2000, Numerical simulation for the residual stresses of stellite hard-facing on carbon steel, Journal of Materials Processing Technology, 101, 1, 70-75

20. Xavier C.R., Delgado H.G. Jr, de Castro J.A., 2015, An experimental and numerical approach for the welding effects on the duplex stainless steel microstructure, Materials Research, 18, $3,489-502$

21. YAng Q.X., YAO M., PARK J., 2004, Numerical simulation on residual stress distribution of hard-face-welded steel specimens with martensite transformation, Materials Science and Engineering A, 364, 1-2, 244-248

22. Yilbas B., Arif A.F.M., Karatas C., Aleem B.J.A., Tabet N., 2010, Laser gas-assisted nitriding of steel: residual stress analysis, Industrial Lubrication and Tribology, 62, 4, 214-223

23. ZamorskiY V.V., 2016, Plasma-jet hard-facing modeling, in IOP Conference Series: Materials Science and Engineering, 134, Institute of Physics Publishing

24. Zargar H.S., Farahani M., Besharati Givi M.K., 2016, Numerical and experimental investigation on the effects of submerged arc welding sequence on the residual distortion of the fillet welded plates, Proceedings of the Institution of Mechanical Engineers, Part B: Journal of Engineering Manufacture, 230, 4, 654-661

25. Zhao C., Stewart D., Jiang J., Dunne F.P.E., 2018, A comparative assessment of iron and cobalt-based hard-facing alloy deformation using HR-EBSD and HR-DIC, Acta Materialia, 159, 173-186

26. Zubairuddin M., Albert S.K., Vasudevan M., Mahadevan S., Chaudhari V., Suri V.K., 2017, Numerical simulation of multi-pass GTA welding of grade 91 steel, Journal of Manufacturing Processes, 27, 87-97

Manuscript received October 18, 2020; accepted for print March 18, 2021 